\title{
A longitudinal study highlights shared aspects of the transcriptomic response to cardiogenic and septic shock
}

Daniele Braga ${ }^{1,2^{*}}$ (D), Matteo Barcella ${ }^{1,2}$, Antoine Herpain $^{3}$, Federico Aletti ${ }^{4}$, Erik B. Kistler ${ }^{5}$, Bernardo Bollen Pinto ${ }^{6}$, Karim Bendjelid ${ }^{6+}$ and Cristina Barlassina ${ }^{1,2+}$

\begin{abstract}
Background: Septic shock (SS) and cardiogenic shock (CS) are two types of circulatory shock with a different etiology. Several studies have described the molecular alterations in SS patients, whereas the molecular factors involved in CS have been poorly investigated. We aimed to assess in the whole blood of CS and SS patients, using septic patients without shock (SC) as controls, transcriptomic modifications that occur over 1 week after ICU admission and are common to the two types of shock.
\end{abstract}

Methods: We performed whole blood RNA sequencing in 21 SS, 11 CS, and 5 SC. In shock patients, blood samples were collected within $16 \mathrm{~h}$ from ICU admission (T1), $48 \mathrm{~h}$ after ICU admission (T2), and at day 7 or before discharge (T3). In controls, blood samples were available at T1 and T2. Gene expression changes over time have been studied in CS, SS, and SC separately with a paired analysis. Genes with $p$ value $<0.01$ (Benjamini-Hochberg multiple test correction) were defined differentially expressed (DEGs). We used gene set enrichment analysis (GSEA) to identify the biological processes and transcriptional regulators significantly enriched in both types of shock.

Results: In both CS and SS patients, GO terms of inflammatory response and pattern recognition receptors (PRRs) were downregulated following ICU admission, whereas gene sets of DNA replication were upregulated. At the gene level, we observed that alarmins, interleukin receptors, PRRs, inflammasome, and DNA replication genes significantly changed their expression in CS and SS, but not in SC. Analysis of transcription factor targets showed in both CS and SS patients, an enrichment of CCAAT-enhancer-binding protein beta (CEBPB) targets in genes downregulated over time and an enrichment of E2F targets in genes with an increasing expression trend.

Conclusions: This pilot study supports, within the limits of a small sample size, the role of alarmins, PRRs, DNA replication, and immunoglobulins in the pathophysiology of circulatory shock, either in the presence of infection or not. We hypothesize that these genes could be potential targets of therapeutic interventions in CS and SS.

Trial registration: ClinicalTrials.gov, NCT02141607. Registered 19 May 2014.

Keywords: Septic shock, Cardiogenic shock, Critical illness, Circulatory shock, RNA-Seq, PRR, Immunoglobulin

\footnotetext{
*Correspondence: daniele.braga@unimi.it

${ }^{\dagger}$ Karim Bendjelid and Cristina Barlassina contributed equally to this work.

${ }^{1}$ Dipartimento di Scienze della Salute, Università degli Studi di Milano, 20142

Milano, Italy

${ }^{2}$ Fondazione Filarete, 20139 Milano, Italy

Full list of author information is available at the end of the article
}

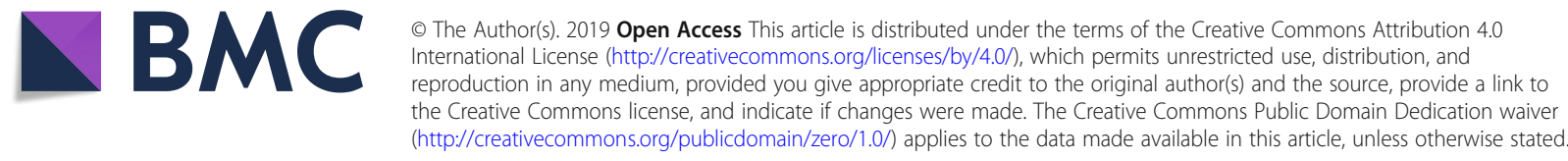




\section{Background}

Circulatory shock is a common life-threatening condition in critical care that affects approximately one third of all patients admitted to the intensive care unit (ICU), with accompanying high mortality [1, 2]. Circulatory shock is characterized by systemic arterial hypotension associated with tissue hypoperfusion, acidemia, and increased blood lactate levels that reflect resultant tissue hypoxia, which in turn may lead to multi-system organ failure and eventual death [3]. Septic shock (SS) and cardiogenic shock (CS) are two forms of circulatory shock with different etiologies but similar end-organ effects. $\mathrm{SS}$, the most common form of shock in the ICU, is a cardiovascular complication of sepsis resulting from a complex interplay of overwhelming systemic inflammation and paradoxical lack of host response, resulting in recalcitrant vasoplegia and variably some degree of cardiac dysfunction [4]. CS, on the other hand, results from acutely depressed cardiac output secondary to cardiac pump failure, with myocardial infarction as its most common cause and systemic inflammation evolving later in response. Both types of circulatory shock are associated with high mortality: $30 \%$ for SS [5] and 40\% in CS [6]. The molecular mechanisms of SS have been widely studied with omic approaches in patient cohorts [7-14]. Conversely, the molecular factors involved in CS have been poorly studied and up to now no -omic data are available. We performed a longitudinal study with a time course RNA sequencing analysis in order to explore the transcriptome in the whole blood of septic and cardiogenic shock patients during the first 7 days of ICU stay. The purpose of this pilot analysis was to highlight the transcriptomic signatures common to CS and SS, using septic patients without shock as controls.

\section{Methods}

\section{Study design and participants}

This study was part of the multicenter prospective observational trial ShockOmics (ClinicalTrials.gov identifier: NCT02141607, EU grant \#602706). Patients were recruited from the ICUs of the Hôpitaux Universitaires de Genève, Université de Genève (Geneva, Switzerland), and Hôpital Erasme, Université Libre de Bruxelles (Brussels, Belgium). The clinical protocol was approved by the ethical committees of the two participating institutions, and informed consent was obtained from the patients or their representatives. In the present study, we included consecutive adult ( $>18$ years old) patients admitted to the ICU for SS or CS with a SOFA score at admission $>6$ and arterial lactate $>2 \mathrm{mmol} / \mathrm{L}$, as previously described [15]. Moreover, patients had to have blood samples, for the analysis of gene expression, collected at three time points: T1, within $16 \mathrm{~h}$ of ICU admission; T2, $48 \mathrm{~h}$ after study enrollment; and T3, on day 7 from ICU admission or before discharge from the ICU. Exclusion criteria were expected death within $24 \mathrm{~h}$ of ICU admission, transfusion of $\geq 4$ units of packed red blood cells or infusion of $\geq 1$ unit of fresh frozen plasma, active hematological malignancy, metastatic cancer, chronic immunosuppression, pre-existing end-stage renal disease requiring renal replacement therapy, recent cardiac surgery, Child-Pugh C cirrhosis, and terminal illness.

Septic patients without shock were included in the study as negative controls. Admission criteria for these patients were a proven or clinically suspected infection, associated with at least one organ dysfunction but the cardiovascular system, as indicated by SOFA score, and lactate levels $<2 \mathrm{mmol} / \mathrm{L}$. In these patients, blood samples were collected at two time points: T1, within $16 \mathrm{~h}$ of ICU admission, and T2, $48 \mathrm{~h}$ after study enrollment.

\section{Analysis of laboratory and clinical variables}

Laboratory and clinical variables measured at the available time points were analyzed using a linear mixed model accounting for fixed effects of time, gender, age, and random effects of patients. We identified the differences between CS, SS, and SC with ANOVA. Demographic variables and variables with one measurement at a single time point were compared using the Wilcoxon rank-sum test or Fisher exact test for categorical variables.

\section{Blood collection and RNA extraction}

Peripheral blood was collected at the time points foreseen by the study design in EDTA tubes with $400 \mu \mathrm{L}$ of $2 \times$ Denaturing solution (Ambion, Austin, TX, USA) and stored at $-20^{\circ} \mathrm{C}$. Total RNA was extracted from $800 \mu \mathrm{L}$ of blood with the MirVana Paris Kit and treated with Turbo DNA-free Kit (Ambion). RNA concentration was estimated with a Nanoquant Infinite M200 instrument (Tecan, Austria). RNA quality was assessed on an Agilent Bioanalyzer using the RNA 6000 Nano Kit (Agilent, Santa Clara, CA, USA), and samples with RNA integrity number $>7.5$ were considered acceptable for processing.

\section{Library preparation}

We prepared sequencing libraries with the TruSeq Stranded Total RNA with Ribo-Zero Globin Kit (Illumina, San Diego, CA, USA) using $800 \mathrm{ng}$ of total RNA input. Final libraries were validated with the Agilent DNA1000 kit and sequenced on a HiSeq2500 platform, producing $50 \times 2$ base paired-end reads.

\section{Sequencing data analysis}

We aligned high-quality paired-end reads to the human reference genome (GRCh38) using STAR (version 2.5.2b) [16], and we selected only uniquely mapping reads. We assigned sequencing reads to genes with featureCounts (version 1.5.1) [17] using the gencode 
(version 25) primary assembly gene transfer file (GTF) as a reference annotation file for genomic feature boundaries.

\section{Exploratory and differential expression analysis}

DESeq2 [18] package built-in functions were used for data preprocessing, exploratory data analysis and analysis of differential gene expression. We studied gene expression changes over time in CS and SS patients and SC separately with a paired analysis, comparing $\mathrm{T} 1$ to T2 in SS and SC and T1 to T3 in CS and SS. Genes with padj < 0.01-Benjamini-Hochberg multiple test correction (FDR)-were considered differentially expressed (DEGs) and used for downstream analysis.

\section{Gene set enrichment analysis}

We first performed gene set enrichment analysis (GSEA) [19] to identify the biological processes enriched in CS, SS, and SC. For this purpose, the lists of genes were ranked for $\log _{2} \mathrm{FC}$ (T2 vs T1 for SS and SC, and T3 vs T1 for CS) and used as input for GSEA, together with the gene set database c5.bp.v6.2.symbols.gmt. As the first step, we selected significant GSEA terms $($ FDR $<0.1)$ in at least one type of shock and filtered for the number of DEGs $\geq 5$ in CS and SS. GOs common to the two types of shock, as well as specific of shock type (CS vs SS), were manually selected from the dataset. Starting from the identified GO terms, we selected a list of genes showing significant modulation over time in CS and SS, but not modulated in SC.

\section{Analysis of transcriptional regulators}

Gene set enrichment analysis of transcription factor targets (TFT) was performed on the lists of CS and SS genes ranked for $\log _{2} \mathrm{FC}$ expression between $\mathrm{T} 1$ and $\mathrm{T} 3$. Enriched gene sets were filtered for FDR $<0.1$ and number of DEGs $\geq 10$.

\section{Results \\ Patients}

Seventy-nine shock patients were recruited between November 2014 and March 2016 in the frame of ShockOmics trial. Twenty-one septic shock and 11 cardiogenic shock patients (Additional file 1) were eligible for the present study, after excluding 16 patients who did not meet the inclusion criteria and 31 patients who did not have blood samples collected at the three time points (Additional file 2). Five septic patients, not developing shock, were recruited as controls (SC) and followed for two time points.

At ICU admission, there were no significant demographic differences between the CS and SS group, including age, BMI, severity of illness (APACHEII), and needs for norepinephrine. In both groups, about $20 \%$ of patients died later in the period from the second to the fourth week, after study enrollment. SOFA and lactate levels decreased over the measured 1 week of ICU stay in all patients. We assessed SOFA score in patients classified according to mortality (alive or dead at 28 days), showing that a decreasing trend of SOFA can be appreciated also in patients who died (Additional file 3). Laboratory results from the blood collected at the three time points of interest, however, revealed significant differences between cardiogenic and septic shock patients for C-reactive protein (CRP) level, lymphocyte count, hematocrit, and fibrinogen $(p<0.05)$ (Table 1). Diastolic blood pressure, mean arterial pressure, and temperature were significantly different as well (Table 1 ). SC compared to SS patients showed significant lower severity scores (APACHE II and SOFA) at ICU admission (Table 2) and did not develop any circulatory failure later during the course of the ICU stay. Clinical and laboratory variables in SC and SS patients are available in Additional file 7.

\section{Sequencing experiment}

Total RNA libraries were sequenced in several batches, producing $28.61 \mathrm{M} \pm 6.49 \mathrm{M}, 31.32 \mathrm{M} \pm 7.81 \mathrm{M}$, and $28.47 \pm$ 4.37 raw read pairs on average for CS, SS, and SC groups, respectively. Ribosomal depletion was effective for all samples; the rRNA rate on mapped data was negligible in both groups $(0.77 \pm 1.25 \%, 0.80 \pm 0.92 \%$, and $1.38 \pm 1.44 \%$ for CS, SS, and SC, respectively). The percentages of reads mapping to exons $(85.20 \pm 5.66 \%$ exonic rate) and DNase efficiency (3.02 $\pm 1.96 \%$ intergenic rate) were satisfactory in all samples. We obtained on average $12.19 \pm 2.82,14.12 \pm 4.20$, and $13.29 \pm 1.62$ million of uniquely and unambiguously mapped fragments for the CS, SS, and SC groups, respectively.

\section{Gene expression analysis over time}

To explore whole gene expression modifications in CS, SS, and SC patients across the time points of the study, we first performed a principal component analysis (PCA) separately in each group of patients (Fig. 1a-c). PCA was performed on the 2000 most variable genes across samples. This analysis revealed that SS patients mostly clustered together according to time point on PC1, suggesting that the largest gene expression variation in the dataset was related to the time point (Fig. 1b). Also, in SC patients, we could appreciate a difference between the time points (Fig. 1c). In CS, on the contrary, patients clustered according to $\mathrm{T} 3$ only, but not to $\mathrm{T} 1$ and $\mathrm{T} 2$, suggesting minor gene expression changes between these two time points (Fig. 1a). Following this analysis, we independently identified genes that are differentially expressed (DEGs) in CS, SS, and SC patients over time. We found that SS patients modulated a higher number of genes compared 
Table 1 Clinical and laboratory variables with follow-up for 1 week

\begin{tabular}{|c|c|c|c|c|c|}
\hline Clinical variable & Shock & T1 & $\mathrm{T} 2$ & T3 & $p$ value \\
\hline \multirow[t]{2}{*}{ Heart rate, bpm } & CS & $87(9)$ & $90(15)$ & $92(23)$ & 0.69532 \\
\hline & SS & $91(22)$ & $81(13)$ & $88(22)$ & \\
\hline \multirow[t]{2}{*}{ Systolic blood pressure, mmHg } & CS & $84(11)$ & $105(24)$ & $113(34)$ & 0.31639 \\
\hline & SS & $83(11)$ & $97(16)$ & $110(17)$ & \\
\hline \multirow[t]{2}{*}{ Diastolic blood pressure, $\mathrm{mmHg}$} & CS & $51(7)$ & $52(9)$ & $63(17)$ & 0.01147 \\
\hline & SS & $45(4)$ & $49(5)$ & $53(12)$ & \\
\hline \multirow[t]{2}{*}{ Mean arterial pressure, $\mathrm{mmHg}$} & CS & $61(6)$ & $69(14)$ & $79(21)$ & 0.04505 \\
\hline & SS & $57(5)$ & $64(7)$ & $72(12)$ & \\
\hline \multirow[t]{2}{*}{ Respiratory rate, rpm } & CS & $21(5)$ & $26(7)$ & $27(3)$ & 0.82505 \\
\hline & SS & $25(8)$ & $25(6)$ & $27(8)$ & \\
\hline \multirow[t]{2}{*}{$\mathrm{PaO}_{2}, \mathrm{mmHg}$} & CS & $92(44)$ & $79(15)$ & $77(12)$ & 0.17879 \\
\hline & SS & $85(17)$ & $76(18)$ & $70(11)$ & \\
\hline \multirow[t]{2}{*}{$\mathrm{PaCO}_{2}, \mathrm{mmHg}$} & CS & $35.0(13.7)$ & $39.3(6.5)$ & $38.8(5.6)$ & 0.10633 \\
\hline & SS & $44.1(13.0)$ & $40.3(8.5)$ & $38.5(6.9)$ & \\
\hline \multirow[t]{2}{*}{$\mathrm{SvCO}_{2} \%$} & CS & $64(11)$ & $67(5)$ & $86(7)$ & 0.49098 \\
\hline & SS & $73(6)$ & $69(8)$ & $61(17)$ & \\
\hline \multirow[t]{2}{*}{$\mathrm{FiO}_{2}$} & CS & $0.59(0.30)$ & $0.35(0.08)$ & $0.33(0.08)$ & 0.87275 \\
\hline & SS & $0.52(0.20)$ & $0.34(0.10)$ & $0.33(0.08)$ & \\
\hline \multirow[t]{2}{*}{$\mathrm{PaO}_{2} / \mathrm{FiO}_{2}$} & CS & $189(109)$ & $239(70)$ & $250(73)$ & 0.51411 \\
\hline & SS & $194(103)$ & $245(89)$ & $229(64)$ & \\
\hline \multirow[t]{2}{*}{ Temperature, ${ }^{\circ} \mathrm{C}$} & CS & $36.7(1.5)$ & $37.3(0.8)$ & $36.7(1.0)$ & 0.01178 \\
\hline & SS & $37.6(0.9)$ & $37.5(0.9)$ & $37.5(1.3)$ & \\
\hline \multirow[t]{2}{*}{ Urine output, mL/day } & CS & $1492(851)$ & $2184(926)$ & $1963(1323)$ & 0.18808 \\
\hline & SS & $1494(831)$ & $2272(1057)$ & 2591 (1219) & \\
\hline \multirow[t]{2}{*}{ Fluid balance, mL } & CS & $1427(1417)$ & $197(1104)$ & $-17(1267)$ & 0.59677 \\
\hline & SS & 2591 (1958) & 411 (1529) & $-815(1358)$ & \\
\hline \multirow[t]{2}{*}{$\mathrm{HCO}_{3}, \mathrm{mmol} / \mathrm{L}$} & CS & $18.1(3.9)$ & $26.0(3.9)$ & $27.6(3.6)$ & 0.57272 \\
\hline & SS & $19.8(3.9)$ & $25.1(4.8)$ & $27.0(5.0)$ & \\
\hline \multirow[t]{2}{*}{ Norepinephrine, $\mu \mathrm{g} /(\mathrm{kg} \min )$} & CS & $0.23(0.2)$ & $0.20(0.22)$ & $0.16(0.13)$ & 0.58250 \\
\hline & SS & $0.35(0.29)$ & $0.23(0.34)$ & $0.05(0.02)$ & \\
\hline \multirow[t]{2}{*}{ Bilirubin, mg/dL } & CS & $1.1(0.6)$ & $0.9(0.4)$ & $0.8(0.6)$ & 0.56664 \\
\hline & SS & $1.6(1.8)$ & $1.2(1.4)$ & $1.0(1.2)$ & \\
\hline \multirow[t]{2}{*}{ Glycemia, mg/dL } & CS & $218.2(73.6)$ & $146.9(25.1)$ & $140.9(54.4)$ & 0.37518 \\
\hline & SS & $183.9(84.8)$ & $142.8(37.9)$ & $129.8(34.3)$ & \\
\hline \multirow[t]{2}{*}{ Prothrombin time INR } & CS & $1.5(0.8)$ & $1.2(0.5)$ & $1.1(0.1)$ & 0.09433 \\
\hline & SS & $1.3(0.3)$ & $1.1(0.2)$ & $1.1(0.2)$ & \\
\hline \multirow[t]{2}{*}{ Fibrinogen, g/L } & CS & $4.11(1.46)$ & $4.34(2.33)$ & $7.15(1.68)$ & 0.02844 \\
\hline & SS & $5.32(2.14)$ & $6.35(2.13)$ & $6.81(1.53)$ & \\
\hline \multirow[t]{2}{*}{ CRP value, mg/L } & CS & $62.8(49.3)$ & $149.7(74.8)$ & $75.5(39.2)$ & 0.00001 \\
\hline & SS & $248.5(140.6)$ & $248.3(112.5)$ & $120.4(71.0)$ & \\
\hline \multirow[t]{2}{*}{ Creatinine, mg/dL } & CS & $1.4(0.5)$ & $1.3(0.6)$ & $1.0(0.4)$ & 0.61095 \\
\hline & SS & $1.9(1.4)$ & $1.4(1.1)$ & $1.1(0.7)$ & \\
\hline \multirow[t]{2}{*}{ Lactate levels, mmol/L } & CS & $4.9(3.6)$ & $1.2(0.4)$ & $1.2(0.5)$ & 0.84012 \\
\hline & SS & $4.3(2.4)$ & $1.7(0.8)$ & $1.2(0.5)$ & \\
\hline
\end{tabular}


Table 1 Clinical and laboratory variables with follow-up for 1 week (Continued)

\begin{tabular}{|c|c|c|c|c|c|}
\hline Clinical variable & Shock & $\mathrm{T1}$ & $\mathrm{T} 2$ & T3 & $p$ value \\
\hline \multirow[t]{2}{*}{ SOFA } & CS & $11.0(2.5)$ & $7.5(2.8)$ & $5.2(3.0)$ & \multirow[t]{2}{*}{0.36026} \\
\hline & SS & $12.1(2.0)$ & $8.8(3.0)$ & $5.5(3.3)$ & \\
\hline \multirow[t]{2}{*}{ Glasgow Coma Scale } & CS & $6(4)$ & $10(3)$ & $13(3)$ & \multirow[t]{2}{*}{0.36746} \\
\hline & SS & $5(4)$ & $9(3)$ & $11(3)$ & \\
\hline \multirow[t]{2}{*}{ Platelets, $10^{3} / \mathrm{mm}^{3}$} & CS & $260(85)$ & $208(80)$ & $295(138)$ & \multirow[t]{2}{*}{0.16299} \\
\hline & SS & $205(103)$ & $176(84)$ & $235(107)$ & \\
\hline \multirow[t]{2}{*}{ Hematocrit \% } & CS & $39.2(4.0)$ & $34.9(4.9)$ & $35.2(4.4)$ & \multirow[t]{2}{*}{0.00360} \\
\hline & SS & $34.6(5.0)$ & $30.2(5.2)$ & $31.4(4.4)$ & \\
\hline \multirow[t]{2}{*}{ Leukocytes total, $10^{3} / \mathrm{mm}^{3}$} & $\mathrm{CS}$ & $15.92(5.36)$ & $12.09(4.20)$ & $10.83(2.93)$ & \multirow[t]{2}{*}{0.90718} \\
\hline & SS & 16.19 (13.94) & $14.55(7.67)$ & $13.66(5.36)$ & \\
\hline \multirow[t]{2}{*}{ White blood cells, $10^{9} / \mathrm{L}$} & CS & $15.29(6.00)$ & $12.2(4.61)$ & $11.29(2.95)$ & \multirow[t]{2}{*}{0.98992} \\
\hline & SS & $15.96(14.22)$ & $14.49(7.95)$ & $13.98(5.59)$ & \\
\hline \multirow[t]{2}{*}{ Lymphocytes, $10^{9} / \mathrm{L}$} & CS & $1.41(0.70)$ & $1.37(0.65)$ & $1.54(0.67)$ & \multirow[t]{2}{*}{0.00007} \\
\hline & SS & $0.70(0.60)$ & $0.80(0.54)$ & $0.90(0.47)$ & \\
\hline \multirow[t]{2}{*}{ Neutrophils, $10^{9} / \mathrm{L}$} & CS & $10.75(6.27)$ & $10.50(5.95)$ & $7.60(1.38)$ & \multirow[t]{2}{*}{0.10346} \\
\hline & SS & $14.49(7.22)$ & $11.32(2.25)$ & $12.14(2.75)$ & \\
\hline
\end{tabular}

Clinical and laboratory characteristics of the patients divided by cardiogenic shock (CS) and septic shock (SS). Data are presented as mean (SD). $p$ values were calculated with ANOVA and describe the significance of the difference between the variables in cardiogenic shock and septic shock over the three time points

to CS patients both in the comparison T2 vs T1 $(\mathrm{CS}=12, \mathrm{SS}=3474)$ and $\mathrm{T} 3$ vs $\mathrm{T} 1 \quad(\mathrm{CS}=1073, \mathrm{SS}=$ 6173). In the SC group, we detected 130 DEGs in the comparison $\mathrm{T} 2$ vs $\mathrm{T} 1$.

\section{Gene set enrichment analysis}

Based on the exploratory analysis, we analyzed with GSEA the genes identified in each group, with the aim to pinpoint overrepresented classes of genes and Gene Ontology (GO) terms that describe the underlying biological processes. We used as input for GSEA the genes of the comparison between T1 and T2, separately in SS and SC. In CS, we analyzed the comparison $\mathrm{T} 1$ vs $\mathrm{T} 3$, because this is the time frame in which relevant gene expression differences were observed. We first selected GO terms significantly enriched in at least 1 type of shock, and we found a total of 315 downregulated and 78 upregulated biological processes (Additional file 4). GO terms of the inflammatory response and pattern recognition receptors (PRR) were downregulated over time, whereas GO terms related to DNA replication were upregulated in both CS and SS. We selected a list of inflammatory, PRR, and DNA replication genes showing significant modulation over time in CS and SS but not modulated in SC (Fig. 2, Table 3). In detail, we observed a negative expression trend for alarmins (S100A8, S100A9, S100A12), components of the inflammasome (NAIP, NLRC4), genes related to interleukin receptors (IL10RB, IL17RA, IL4R), transcription

Table 2 Clinical variables

\begin{tabular}{|c|c|c|c|c|c|}
\hline Clinical variable & $\mathrm{CS}(n=11)$ & SS $(n=21)$ & $\mathrm{SC}(n=5)$ & $p$ value SS vs CS & $p$ value SS vs SC \\
\hline Age, years & $68.7(13.0)$ & $67.5(19.2)$ & $72.4(15.8)$ & 0.937 & 0.696 \\
\hline Body mass index, $\mathrm{kg} / \mathrm{m}^{2}$ & $27.8(6.9)$ & $27.2(5.5)$ & $22.1(6.9)$ & 0.721 & 0.111 \\
\hline Sex, males & $10(90.9 \%)$ & $14(66.6 \%)$ & $3(60.0 \%)$ & 0.210 & 1.000 \\
\hline Length of stay in ICU, days & $7.6(3.3)$ & $9.2(6.0)$ & $6.0(6.7)$ & 0.920 & 0.046 \\
\hline Length of stay in hospital, days & $24.2(18.3)$ & $28.0(19.5)$ & $28.0(26.1)$ & 0.676 & 0.696 \\
\hline APACHE $\|(T 1)$ & $22.73(7.34)$ & $24.57(7.51)$ & $14.6(3.0)$ & 0.450 & 0.012 \\
\hline SOFA (T1) & $11.0(2.5)$ & $12.1(2.0)$ & $6.2(2.2)$ & 0.360 & 0.001 \\
\hline Mortality (28 days) & $2(18.2 \%)$ & $5(23.8 \%)$ & $0(0 \%)$ & 1.000 & 0.545 \\
\hline
\end{tabular}

Clinical characteristics of the patients divided by cardiogenic shock (CS), septic shock (SS), and septic controls (SC). Data are presented as mean (SD) or frequency (\%). $p$ values were calculated with Wilcoxon rank-sum test or alternatively with Fisher exact test for categorical variables 


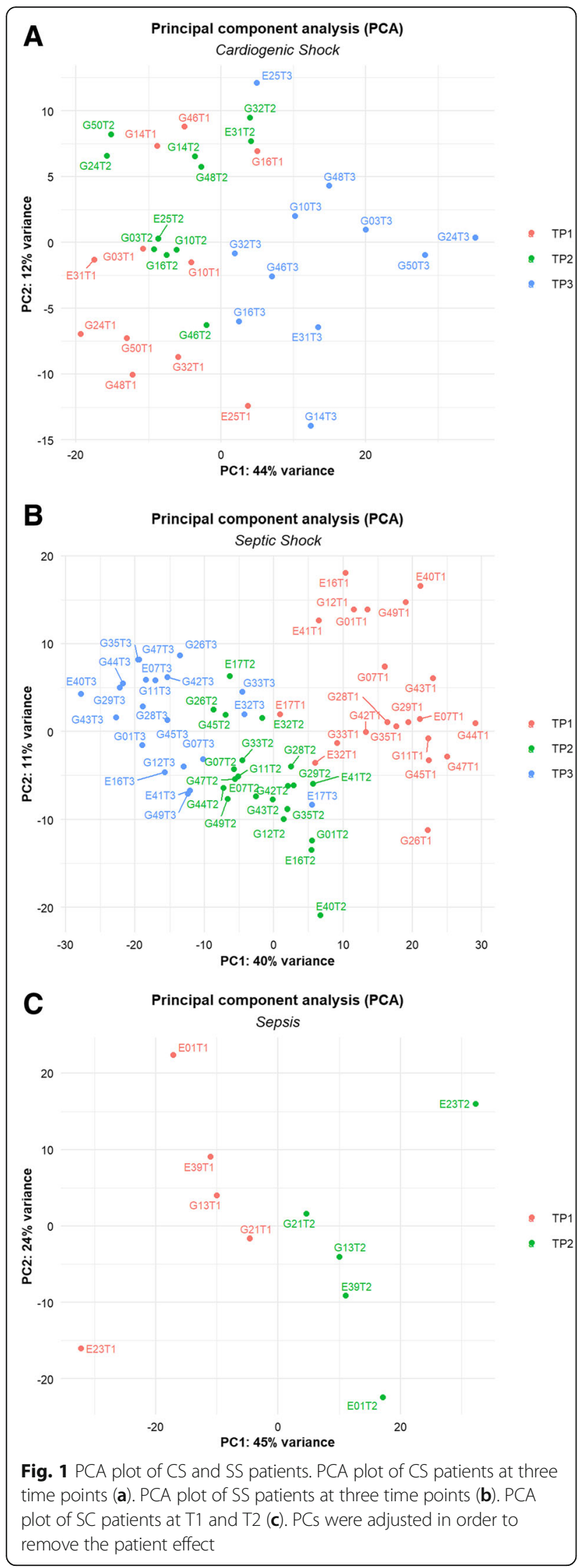

factors (CEBPB, PPARG, RBPJ, BCL6), Toll-like receptors (TLR1, TLR4, TLR8), and C-type lectin receptors (CLEC5A, CLEC6A). A positive expression trend was observed for genes essential for DNA replication (MCM2, MCM3, MCM5, MCM7). We also estimated the gene expression modifications in SS and CS comparing $\mathrm{T} 1$ to T3. In SS patients only, we found increasing expression of genes involved in defense response to bacteria and lymphocyte-mediated immunity, as well as decreasing expression of genes involved in platelet function and carbohydrate catabolic processes (Additional file 5, Additional file 8). Immunoglobulin genes encoding the heavy constant chains (IGHA1, IGHA2, IGHG1, IGHG2, IGHG3, IGHG4, IGHGP, IGHM) and the variable heavy and light chains (IGHV, IGKV, IGLV gene classes) were upregulated over 1 week of observation in both types of shock (Table 4).

\section{Analysis of transcription factor target genes}

We searched for overrepresented transcription factor targets in the lists of genes ranked according to $\log _{2} \mathrm{FC}$ in the CS and SS groups separately. GSEA results are as shown in Additional file 6. Then, we focused on the common enriched transcription factors: we observed that genes with a negative expression trend were enriched in target sequences of CCAAT-enhancer-binding protein beta (CEBPB), whereas positively regulated genes were enriched in target sequences of the members of the E2F family of transcription factors (Table 5, Fig. 3).

\section{Discussion}

This study describes the transcriptome profile of circulating cells in CS and SS patients over the first week after ICU admission, using septic patients without shock as controls. The study design is based on three time points (T1, T2, T3) over 1 week of observation in shock patients and two time points (T1, T2) in septic controls. To our knowledge, an analysis with this time frame from shock onset is new in the field of SS research, and this is the first transcriptomic study in CS.

At study enrollment, illness severity, evaluated as SOFA score and lactate level, was comparable between CS and SS patients and decreased during 1 week of ICU stay. The dosage of norepinephrine needed to maintain blood pressure was also similar between the two groups, demonstrating a comparable degree of vasoplegia. However, significant differences were found in the levels of C-reactive protein and lymphocyte count that could be explained by the pathophysiology of the two types of shock.

Within-group transcriptomic analysis over time showed differences in the number of genes modulated in SS and CS during the period of observation, with a larger number 


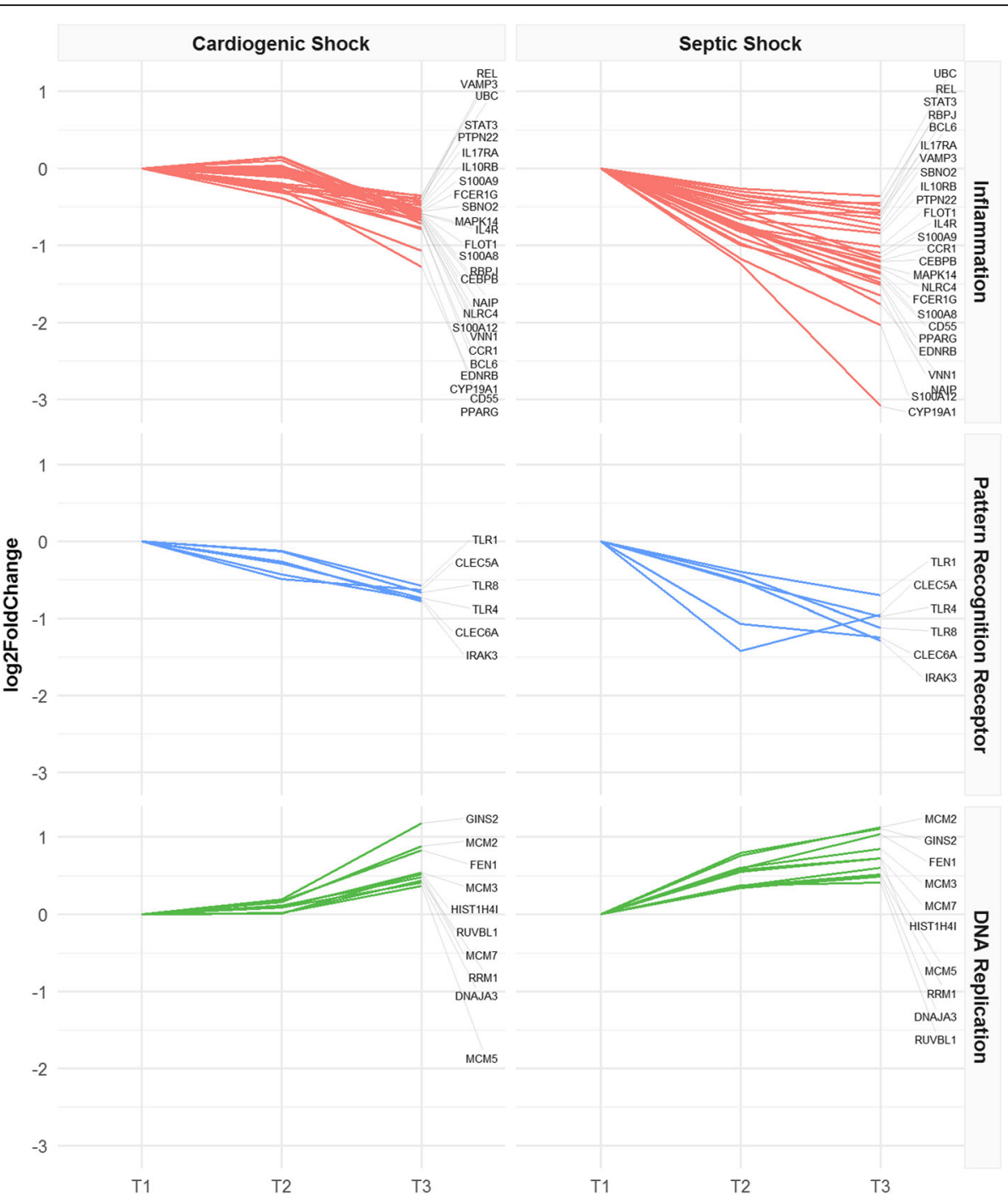

Fig. 2 Inflammatory pathway, pattern recognition receptors, and DNA replication. Expression trends of significantly modulated genes in CS and SS, but not in SC patients. Data are normalized on T1; $\log _{2}$ FoldChanges are plotted

of differentially expressed genes identified in SS compared to CS. The timing of gene expression modulation was different as well, compared to the time of shock diagnosis (T1). SS patients showed significant modifications both in the early phase that corresponds to $\mathrm{T} 2$ and after 7 days of ICU stay (T3), whereas in CS patient, relevant and significant transcriptomic changes occurred only at T3. Differential expression in these time frames identified genes and pathways common to both CS and SS groups, but not found in SC. Among the genes identified in both shock groups, GSEA highlighted a negative expression trend for genes involved in inflammatory processes including alarmins, inflammasome, and interleukin receptors, implying that the acute phase of shock in these patients was characterized by an inflammatory peak that decreased after supportive treatment. From our results, it appears that at the transcriptional level inflammatory processes are more rapidly downregulated in SS (Fig. 2) and more slowly in CS patients. A different timing of the inflammatory processes in CS and SS was also suggested by the trend of CRP serum levels in the three time points (Fig. 4). A similar time course of the expression of C-reactive protein has been previously described by Parenica et al. [20].

In both CS and SS patients, SOFA scores showed a decreasing trend in time, suggesting a link between acute inflammation and organ dysfunction as it has been previously found in acute illness [21]. Pattern recognition receptors (PRRs), including Toll-like receptors (TLRs) and C-type lectin receptors, were downregulated after 1 week in both shock types. PRRs are essential for the 
Table 3 Gene expression changes in inflammatory pathway, pattern recognition receptors, and DNA replication

\begin{tabular}{|c|c|c|c|c|}
\hline Gene name & Category & Molecular function & CS_log $\log _{2} \mathrm{FC}$ T1T3 & SS_log ${ }_{2} F C \_T 1 T 2$ \\
\hline BCL6 & Inflammation & Transcription factor & -0.68 & -0.58 \\
\hline CCR1 & Inflammation & Chemokine receptor & -0.67 & -0.61 \\
\hline CD55 & Inflammation & Regulation of complement cascade & -0.77 & -1.00 \\
\hline CEBPB & Inflammation & Transcription factor & -0.63 & -0.79 \\
\hline CYP19A1 & Inflammation & Aromatase-estrogen synthesis & -1.28 & -1.23 \\
\hline EDNRB & Inflammation & Endothelin receptor & -0.79 & -0.90 \\
\hline FCER1G & Inflammation & Antibody receptor & -0.55 & -0.80 \\
\hline FLOT1 & Inflammation & Vesicle trafficking and cell morphology & -0.60 & -0.77 \\
\hline IL10RB & Inflammation & Interleukin receptor & -0.48 & -0.50 \\
\hline IL17RA & Inflammation & Interleukin receptor & -0.47 & -0.35 \\
\hline IL $4 \mathrm{R}$ & Inflammation & Interleukin receptor & -0.58 & -0.82 \\
\hline MAPK14 & Inflammation & MAPK p38 & -0.58 & -0.75 \\
\hline NAIP & Inflammation & Inflammosome & -0.63 & -0.80 \\
\hline NLRC4 & Inflammation & Inflammosome & -0.63 & -0.73 \\
\hline PPARG & Inflammation & Transcription factor & -1.07 & -0.78 \\
\hline PTPN22 & Inflammation & Tyrosine phosphatase & -0.43 & -0.65 \\
\hline RBPJ & Inflammation & Transcription factor & -0.61 & -0.34 \\
\hline REL & Inflammation & NF-KB subunit & -0.36 & -0.29 \\
\hline $\mathrm{S} 100 \mathrm{~A} 12$ & Inflammation & Alarmin & -0.71 & -1.17 \\
\hline S100A8 & Inflammation & Alarmin & -0.60 & -0.78 \\
\hline S100A9 & Inflammation & Alarmin & -0.53 & -0.54 \\
\hline SBNO2 & Inflammation & Transcriptional regulation of NF-kappaB & -0.56 & -0.38 \\
\hline STAT3 & Inflammation & Transcription factor & -0.42 & -0.43 \\
\hline UBC & Inflammation & Polyubiquitin precursor & -0.38 & -0.26 \\
\hline VAMP3 & Inflammation & Vesicular transport & -0.35 & -0.46 \\
\hline VNN1 & Inflammation & Leucocyte adhesion and migration & -0.67 & -0.97 \\
\hline CLEC5A & Pattern recognition receptor & C-type lectin receptor & -0.63 & -1.42 \\
\hline CLEC6A & Pattern recognition receptor & C-type lectin receptor & -0.75 & -1.07 \\
\hline IRAK3 & Pattern recognition receptor & PRR downstream signaling & -0.78 & -0.51 \\
\hline TLR1 & Pattern recognition receptor & Toll-like receptor & -0.58 & -0.39 \\
\hline TLR4 & Pattern recognition receptor & Toll-like receptor & -0.74 & -0.53 \\
\hline TLR8 & Pattern recognition receptor & Toll-like receptor & -0.66 & -0.44 \\
\hline DNAJA3 & DNA replication & Interactor of DNA polymerase & 0.41 & 0.34 \\
\hline FEN1 & DNA replication & DNA replication and repair & 0.83 & 0.59 \\
\hline GINS2 & DNA replication & DNA replication initiation & 1.18 & 0.79 \\
\hline HIST1H4I & DNA replication & Replication-dependent histone & 0.53 & 0.57 \\
\hline MCM2 & DNA replication & MCM complex & 0.88 & 0.76 \\
\hline MCM3 & DNA replication & MCM complex & 0.54 & 0.60 \\
\hline MCM5 & DNA replication & MCM complex & 0.36 & 0.36 \\
\hline MCM7 & DNA replication & MCM complex & 0.48 & 0.55 \\
\hline RRM1 & DNA replication & Biosynthesis of deoxyribonucleotides & 0.43 & 0.36 \\
\hline RUVBL1 & DNA replication & DNA helicase & 0.51 & 0.37 \\
\hline
\end{tabular}

Genes with significant modulation over time in both CS and SS, but not in SC. Description of functions and $\log _{2}$ FoldChange expression are shown 
Table 4 Gene expression changes of immunoglobulins

\begin{tabular}{|c|c|c|c|c|c|c|}
\hline Gene ID & Gene name & Chain & Region & Antibody class & CS_log 2 FC_T1T3 & SS_log ${ }_{2}$ FC_T1T3 \\
\hline ENSG00000211895 & $|\mathrm{GHA}|$ & Heavy & Constant & $\lg A$ & 1.25 & 1.48 \\
\hline ENSG00000211890 & IGHA2 & Heavy & Constant & $\lg A$ & 1.27 & 1.52 \\
\hline ENSG00000211896 & $|G H G|$ & Heavy & Constant & $\lg G$ & 1.05 & 1.15 \\
\hline ENSG00000211893 & IGHG2 & Heavy & Constant & $\lg G$ & 1.28 & 2.15 \\
\hline ENSG00000211897 & IGHG3 & Heavy & Constant & $\lg G$ & 1.14 & 1.28 \\
\hline ENSG00000211892 & IGHG4 & Heavy & Constant & $\lg G$ & 0.95 & 1.52 \\
\hline ENSG00000253755 & IGHGP & Heavy & Constant & $\lg G$ & 0.99 & 1.30 \\
\hline ENSG00000211899 & IGHM & Heavy & Constant & $\lg M$ & 0.98 & 0.84 \\
\hline ENSG00000211934 & IGHV1-2 & Heavy & Variable & - & 0.92 & 1.25 \\
\hline ENSG00000211935 & IGHV1-3 & Heavy & Variable & - & 0.91 & 1.13 \\
\hline ENSG00000211962 & IGHV1-46 & Heavy & Variable & - & 0.72 & 1.17 \\
\hline ENSG00000211942 & IGHV3-13 & Heavy & Variable & - & 0.89 & 1.36 \\
\hline ENSG00000211943 & IGHV3-15 & Heavy & Variable & - & 1.37 & 1.62 \\
\hline ENSG00000211947 & IGHV3-21 & Heavy & Variable & - & 1.11 & 1.25 \\
\hline ENSG00000211949 & IGHV3-23 & Heavy & Variable & - & 1.35 & 1.30 \\
\hline ENSG00000270550 & IGHV3-30 & Heavy & Variable & - & 1.10 & 1.17 \\
\hline ENSG00000211964 & IGHV3-48 & Heavy & Variable & - & 1.09 & 1.15 \\
\hline ENSG00000211965 & IGHV3-49 & Heavy & Variable & - & 0.87 & 1.22 \\
\hline ENSG00000282639 & IGHV3-64D & Heavy & Variable & - & 1.11 & 1.31 \\
\hline ENSG00000211938 & IGHV3-7 & Heavy & Variable & - & 1.43 & 1.65 \\
\hline ENSG00000225698 & IGHV3-72 & Heavy & Variable & - & 1.73 & 1.46 \\
\hline ENSG00000211976 & IGHV3-73 & Heavy & Variable & - & 1.11 & 1.73 \\
\hline ENSG00000224650 & IGHV3-74 & Heavy & Variable & - & 1.24 & 1.56 \\
\hline ENSG00000211959 & IGHV4-39 & Heavy & Variable & - & 0.87 & 1.08 \\
\hline ENSG00000276775 & IGHV4-4 & Heavy & Variable & - & 0.93 & 1.26 \\
\hline ENSG00000224373 & IGHV4-59 & Heavy & Variable & - & 1.11 & 1.05 \\
\hline ENSG00000211966 & IGHV5-51 & Heavy & Variable & - & 0.85 & 1.00 \\
\hline ENSG00000211933 & IGHV6-1 & Heavy & Variable & - & 1.25 & 1.16 \\
\hline ENSG00000211592 & IGKC & Light & Constant & - & 1.30 & 1.48 \\
\hline ENSG00000211597 & IGKJ1 & Light & Joining & - & 0.89 & 1.21 \\
\hline ENSG00000211594 & IGKJ4 & Light & Joining & - & 0.89 & 1.19 \\
\hline ENSG00000243290 & IGKV1-12 & Light & Variable & - & 1.28 & 0.94 \\
\hline ENSG00000240864 & IGKV1-16 & Light & Variable & - & 1.11 & 1.01 \\
\hline ENSG00000240382 & IGKV1-17 & Light & Variable & - & 1.26 & 1.43 \\
\hline ENSG00000244575 & IGKV1-27 & Light & Variable & - & 1.21 & 1.05 \\
\hline ENSG00000243466 & IGKV1-5 & Light & Variable & - & 1.10 & 1.39 \\
\hline ENSG00000239855 & IGKV1-6 & Light & Variable & - & 1.07 & 1.65 \\
\hline ENSG00000241755 & IGKV1-9 & Light & Variable & - & 1.08 & 1.17 \\
\hline ENSG00000241294 & IGKV2-24 & Light & Variable & - & 1.13 & 1.71 \\
\hline ENSG00000243238 & IGKV2-30 & Light & Variable & - & 1.24 & 1.50 \\
\hline ENSG00000243264 & IGKV2D-29 & Light & Variable & - & 1.10 & 1.32 \\
\hline ENSG00000241351 & IGKV3-11 & Light & Variable & - & 1.43 & 1.14 \\
\hline ENSG00000244437 & IGKV3-15 & Light & Variable & - & 1.08 & 1.23 \\
\hline ENSG00000239951 & IGKV3-20 & Light & Variable & - & 1.20 & 1.46 \\
\hline
\end{tabular}


Table 4 Gene expression changes of immunoglobulins (Continued)

\begin{tabular}{|c|c|c|c|c|c|c|}
\hline Gene ID & Gene name & Chain & Region & Antibody class & CS_log 2 FC_T1T3 & SS_log ${ }_{2} \mathrm{FC} \_\mathrm{T} 1 \mathrm{TT}$ \\
\hline ENSG00000211625 & IGKV3D-20 & Light & Variable & - & 1.02 & 1.31 \\
\hline ENSG00000211598 & IGKV4-1 & Light & Variable & - & 1.27 & 1.72 \\
\hline ENSG00000211677 & IGLC2 & Light & Constant & - & 1.26 & 1.52 \\
\hline ENSG00000211679 & IGLC3 & Light & Constant & - & 1.32 & 1.45 \\
\hline ENSG00000211642 & IGLV10-54 & Light & Variable & - & 1.09 & 1.17 \\
\hline ENSG00000211653 & IGLV1-40 & Light & Variable & - & 1.05 & 1.21 \\
\hline ENSG00000211651 & IGLV1-44 & Light & Variable & - & 0.97 & 1.32 \\
\hline ENSG00000211648 & IGLV1-47 & Light & Variable & - & 1.03 & 1.63 \\
\hline ENSG00000211644 & IGLV1-51 & Light & Variable & - & 1.16 & 1.24 \\
\hline ENSG00000211668 & IGLV2-11 & Light & Variable & - & 1.08 & 1.57 \\
\hline ENSG00000211666 & IGLV2-14 & Light & Variable & - & 1.21 & 1.62 \\
\hline ENSG00000211660 & IGLV2-23 & Light & Variable & - & 1.21 & 1.70 \\
\hline ENSG00000278196 & IGLV2-8 & Light & Variable & - & 1.44 & 1.57 \\
\hline ENSG00000211673 & IGLV3-1 & Light & Variable & - & 0.79 & 1.15 \\
\hline ENSG00000211663 & IGLV3-19 & Light & Variable & - & 0.82 & 1.21 \\
\hline ENSG00000211662 & IGLV3-21 & Light & Variable & - & 0.89 & 1.08 \\
\hline ENSG00000211637 & IGLV4-69 & Light & Variable & - & 0.94 & 1.19 \\
\hline ENSG00000211650 & IGLV5-45 & Light & Variable & - & 0.83 & 0.96 \\
\hline ENSG00000211640 & IGLV6-57 & Light & Variable & - & 1.08 & 1.33 \\
\hline ENSG00000211652 & IGLV7-43 & Light & Variable & - & 1.13 & 1.65 \\
\hline ENSG00000211649 & IGLV7-46 & Light & Variable & - & 1.06 & 1.76 \\
\hline ENSG00000211638 & IGLV8-61 & Light & Variable & - & 1.13 & 1.62 \\
\hline
\end{tabular}

Genes with significantly different expression in both CS and SS over 1 week. Description of functions and log ${ }_{2}$ FoldChange expression are shown

early detection of pathogens and the initiation of an adequate innate immune response $[22,23]$, and they play a well-known role in the development and pathogenesis of sepsis [24]. PRRs can also be activated by damageassociated molecular patterns (DAMPs) [25-27], which act as triggers of inflammation, cell injury, vascular leakage, and multiple organ dysfunction in acute illness $[24,28,29]$. This may be a possible explanation for the inflammatory modulation observed in CS patients, as the involvement of pattern recognition receptor signaling and inflammatory mediators has been documented in the pathogenesis of heart failure [30-32] and lung injury
[33]. Transcription factors with inflammation-related associations also displayed a decreasing expression trend, including peroxisome proliferator-activated receptor gamma (PPARG), a regulator of inflammation and the lipid pathway, and CCAAT-enhancer-binding protein beta (CEBPB), which is necessary for normal macrophage inflammatory response [34]. Decreases in these inflammation-related transcription factors correlated significantly with the decreased expression of a set of genes related to inflammation and immunity.

During the critical illness period from T1 to T3, we observed a positive expression trend of DNA replication

Table 5 GSEA of transcription factor targets (TFT)

\begin{tabular}{llllllll}
\hline Gene set (TFT) & CS_NES & SS_NES & CS_FDR.q.val & SS_FDR.q.val & DEGs_CS & DEGs_SS & Trend \\
\hline CEBPB_02 & -1.80 & -1.87 & 0.08739 & 0.02342 & 23 & 56 & Negative \\
E2F_Q3_01 & 1.99 & 1.64 & 0.00111 & 0.02955 & 20 & 54 & Positive \\
E2F_Q4_01 & 1.89 & 1.87 & 0.00144 & 0.01000 & 20 & 57 & Positive \\
E2F_Q6 & 1.95 & 1.55 & 0.00117 & 0.06391 & 18 & 58 & Positive \\
E2F_Q6_01 & 1.93 & 1.65 & 0.00128 & 0.03002 & 20 & 54 & Positive \\
E2F1_Q4_01 & 1.92 & 1.63 & 0.00123 & 0.03049 & 20 & 52 & Positive \\
\hline
\end{tabular}

For each gene set of TFT is reported: normalized enriched score, false discovery rate, the number of target genes differentially expressed in CS and SS, and the gene expression trend 


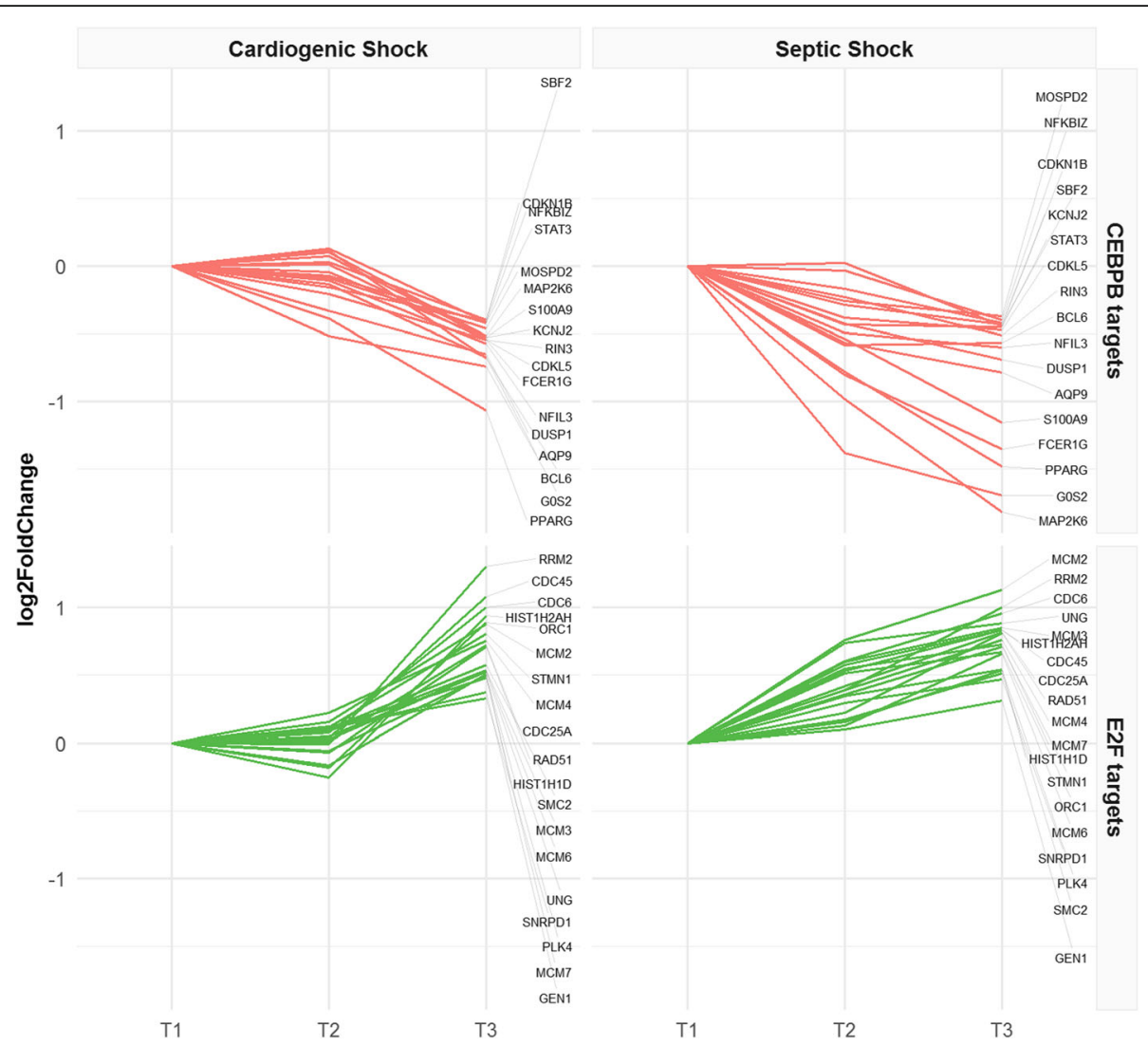

Fig. 3 Gene expression trends of enriched transcription factor targets in CS and SS. CEBPB and E2F target genes are shown. Data are normalized on $\mathrm{T} 1$; $\log _{2}$ FoldChanges are plotted

genes (Fig. 2) in both SS and CS groups, suggesting that during shock, at least, a subset of circulating cells undergoes a process of self-renewal. In this time frame, we also observed the upregulation of immunoglobulins, implying an activation of the adaptive immune system that is co-existent with innate immune system downregulation. Consistent with our observations, low serum levels of circulating immunoglobulins have been described at septic shock onset [35-37], and Venet et al. observed their increase to reference levels after 5-7 days [38]. Interestingly, the increasing trend of immunoglobulin gene transcription in SS was also observed in CS patients, suggesting that Igs may also have a role in the absence of infection. This is in agreement with the findings of Andaluz-Ojeda et al. who investigated the role of Ig in non-septic critically ill patients [39]. The role of Igs in the absence of infection may be related both to the detection of DAMPs [40] and to the immunomodulatory activity of the adaptive immune response [41]. The analysis of transcription factor targets in the CS and SS groups revealed a significant enrichment of genes regulated by the E2F transcription factor family, which are involved in the control of cell cycle progression and cell proliferation [42, 43].
In this study, we could also focus on genes that modify their expression uniquely in SS. In these patients, as expected, specific transcriptomic modifications were observed in genes involved in the response to infection, lymphocyte-mediated immunity, carbohydrate metabolism, and platelet function. These processes are implicated in the pathophysiology of sepsis and have already been described in previous works [44-46]. In CS patients, our study was unable to detect any specifically modulated pathway in the blood cells; transcriptional modifications observed in this group were associated with biological functions common to SS.

The present work has two limitations. The first is the small sample size, which could hamper the detection of small, but still relevant gene expression changes. Moreover, studies of large cohorts [47] and the poor success of the past clinical trials [48] showed that sepsis is a heterogeneous condition, with high between-patient variability, and looking at a small cohort of patients make difficult the identification of different phenotype subgroups. The same concept is extendible to cardiogenic shock patients, as they also could show phenotypes or different heart failure and circulatory shock mechanisms [32]. To partially overcome between-patient variability, we used a 


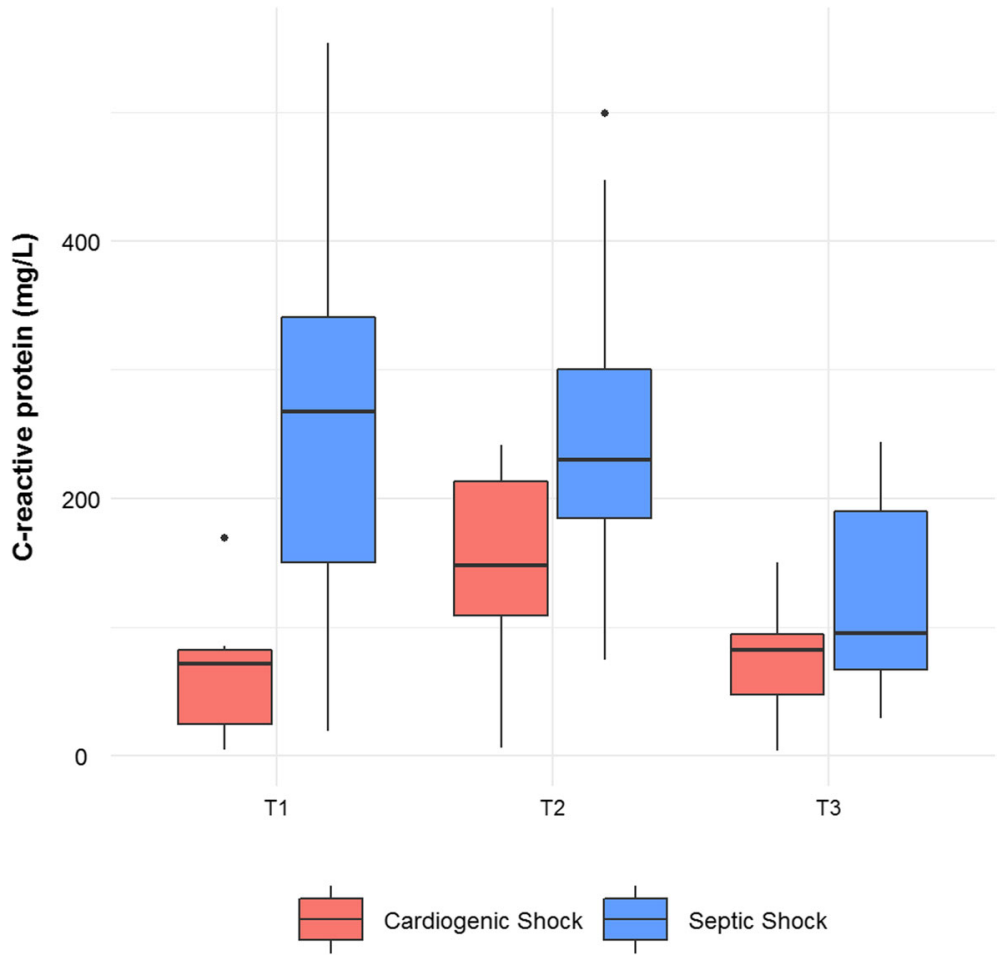

Fig. 4 Boxplots of C-reactive protein serum measurements. C-reactive protein measurements $(\mathrm{mg} / \mathrm{L})$ in cardiogenic and septic shock patients measured at three time points. The lower and upper hinges correspond to the 25 th and 75 th percentiles, respectively

paired analysis to assess the gene expression changes, which takes advantage of the within-patient correlation between the time points, strengthens the analysis, and improves the statistical power.

A second limitation is that, since we used a study design based on three time points, we have excluded the most severe patients who died before the second or third time point. Thus, the results of our study describe only patients surviving at least 1 week, whereas patients who died early could have different expression signals. The exclusion of the most severe patients can also explain why mortality in our shock patients was low in comparison with broader modern clinical trials or large surveys. In addition, in our cardiogenic shock patients, the amount of CS not related to an acute coronary syndrome was $7 / 11$ (Additional file 1), a condition that is associated with a mortality rate $<25 \%$ as reported by Harjola et al. [49].

In short, our study pinpoints a common modulation in SS and CS patients of genes of inflammation, PRRs, DNA replication, and immunoglobulins, irrespective of the etiology. These pathways have been previously investigated in SS, and their perturbation can be interpreted as the response of the immune system to a widespread infection. Their modulation in CS patients suggests that their role may be independent of infection and sepsis and should rather be seen in the context of dysfunctions associated with circulatory shock. The overlap in molecular patterns observed in this study suggests shared mechanistic pathways between CS and SS. This could help to identify common targets for more personalized therapies that can be used in different critical illness conditions [50], as previously demonstrated and is ongoing in cancer research [51].

\section{Conclusions}

Our preliminary results support a central role for acute inflammatory processes in the pathophysiology of shock, with the hypothesis that pattern recognition receptors, alarmins, and immunoglobulins may serve as mediators. This study has the limit of a small sample size. However, it encourages new -omics studies in larger cohorts of circulatory shock patients to investigate the relationships of PRRs, inflammation, and immunoglobulins with outcomes.

\section{Supplementary information}

Supplementary information accompanies this paper at https://doi.org/10. 1186/s13054-019-2670-8.

Additional file 1: Table S1. Description of CS, SS and SC patients included in the study. For each patient is reported the type of shock, 
gender and age, mortality at 28 days. The cause for CS is specified for CS patients, whereas for SS and SC patients the source of infection is indicated.

Additional file 2: Figure S1. Flow Chart of the process of patient recruitment. Description of the process of selection of the patients included in the study.

Additional file 3: Figure S2. SOFA score trends in CS and SS patients according to mortality. Boxplots of SOFA scores evaluated at three timepoints in CS and SS patients according to the mortality at 28 days.

Additional file 4. Results of GSEA of Gene Ontologies in CS and SS. Upregulated (Excel Sheet "GSEA_UP") and downregulated (Excel Sheet "GSEA_DOWN") gene sets resulting from the GSEA analysis in CS, SS and SC. For each significantly enriched GO is reported the number of DEGs, the Normalized Enriched Score (NES), the False Discovery Rate (FDR.q.val).

Additional file 5: Figure S3. Gene expression trends of biological processes enriched only in SS patients. Gene expression trends of biological processes related to defense response to bacterium, lymphocyte mediate immunity, platelet activation and degranulation, carbohydrate catabolic process. Data are normalized on T1, $\log _{2}$ FoldChanges are plotted.

Additional file 6. Results of the GSEA of Transcription Factor Targets (TFT). Results table of the GSEA analysis of genes ranked for $\log _{2}$ FC over one week in CS and SS. For each gene set of TFT is reported: number of DEGs and number of genes in the gene set (SIZE), Normalized Enriched Score, False Discovery Rate and type of shock.

Additional file 7. Clinical variables of SS and SC patients. Clinical characteristics of the patients divided by Septic Shock and Septic Controls. Data are presented as mean (SD). P-values were calculated with ANOVA and describe the significance of the difference between the variables in Septic Shock and Septic Controls over 2 timepoints.

Additional file 8. Gene expression trends of biological processes enriched only in SS patients. Extensive information of genes shown in Figure $\mathrm{S} 3$ is reported in this table. Data are normalized on $\mathrm{T} 1$, $\log _{2}$ FoldChanges are shown.

\section{Abbreviations}

ICU: Intensive care unit; SS: Septic shock; CS: Cardiogenic shock; SC: Septic controls (not developing shock); SOFA: Sequential Organ Function Assessment; DEG: Differentially expressed gene; FDR: False discovery rate; GSEA: Gene set enrichment analysis; GO: Gene Ontology; BMI: Body mass index; PCA: Principal component analysis; T1: Time point 1; T2: Time point 2; T3: Time point 3; Ig: Immunoglobulin; PRR: Pattern recognition receptor; DAMP: Damage-associated molecular pattern; TLR: Toll-like receptor

\section{Acknowledgements}

Not applicable

\section{Authors' contributions}

$\mathrm{CB}, \mathrm{KB}, \mathrm{DB}, \mathrm{BBP}, \mathrm{AH}$, and $\mathrm{MB}$ contributed to the study concept and design. $\mathrm{DB}$ performed the laboratory work. $\mathrm{BBP}, \mathrm{AH}$, and $\mathrm{KB}$ were in charge of the clinical work. $D B$ and $M B$ performed the statistical and bioinformatics analyses. $C B, D B, K B, A H, F A$, and EK contributed to the drafting of the manuscript. All authors approved the final version of the manuscript.

\section{Funding}

This study was supported by "ShockOmics" grant 602706 of the European Union.

\section{Availability of data and materials}

The datasets generated and analyzed during the current study are available through the Gene Expression Omnibus Database (accession number GSE131411).

\section{Ethics approval and consent to participate}

The Geneva Regional Research Ethics Committee (Commission cantonale d'etique de la recherché or CCER) (Geneva, Switzerland) and the Universite Libre de Bruxelles (Brussels, Belgium) approved the clinical protocol.
Informed consent was obtained from the participants or their representatives.

\section{Consent for publication}

Not applicable

\section{Competing interests}

The authors declare that they have no competing interests.

\section{Author details}

${ }^{1}$ Dipartimento di Scienze della Salute, Università degli Studi di Milano, 20142 Milano, Italy. ${ }^{2}$ Fondazione Filarete, 20139 Milano, Italy. ${ }^{3}$ Department of Intensive Care, Hôpital Erasme, Université Libre de Bruxelles, Brussels, Belgium. ${ }^{4}$ Department of Bioengineering, University of California San Diego, La Jolla, CA, USA. ${ }^{5}$ Department of Anestesiology \& Critical Care, University of California, San Diego, USA. ${ }^{6}$ Department of Anaesthesia, Pharmacology and Intensive Care, Geneva University Hospitals, Geneva, Switzerland.

Received: 25 May 2019 Accepted: 12 November 2019

Published online: 19 December 2019

References

1. Vincent J-L, De Backer D. Circulatory shock. N Engl J Med. 2013;369:1726-34

2. Cecconi M, De Backer D, Antonelli M, Beale R, Bakker J, Hofer C, et al. Consensus on circulatory shock and hemodynamic monitoring. Task Force of the European Society of Intensive Care Medicine. Intensive Care Med. 2014:40:1795-815.

3. Daviaud F, Grimaldi D, Dechartres A, Charpentier J, Geri G, Marin N, et al. Timing and causes of death in septic shock. Ann Intensive Care. 2015;5:16.

4. Shankar-Hari M, Phillips GS, Levy ML, Seymour CW, Liu VX, Deutschman CS, et al. Developing a new definition and assessing new clinical criteria for septic shock. JAMA. 2016;315:775-87.

5. Cecconi M, Evans L, Levy M, Rhodes A. Sepsis and septic shock. Lancet. 2018;392:75-87.

6. Van Diepen S, Katz JN, Albert NM, Henry TD, Jacobs AK, Kapur NK, et al. Contemporary management of cardiogenic shock: a scientific statement from the American Heart Association. Circulation. 2017;136:e232-68.

7. Cazalis M-A, Lepape A, Venet F, Frager F, Mougin B, Vallin H, et al. Early and dynamic changes in gene expression in septic shock patients: a genomewide approach. Intensive Care Med Exp. 2014;2:20.

8. Almansa R, Heredia-Rodriguez M, Gomez-Sanchez E, Andaluz-Ojeda D, Iglesias $V$, Rico L, et al. Transcriptomic correlates of organ failure extent in sepsis. J Inf Secur. 2015;70:445-56.

9. Burnham KL, Davenport EE, Radhakrishnan J, Humburg P, Gordon AC, Hutton $P$, et al. Shared and distinct aspects of the sepsis transcriptomic response to fecal peritonitis and pneumonia. Am J Respir Crit Care Med. 2017;196:328-39.

10. Kalenka A, Feldmann RE, Otero K, Maurer MH, Waschke KF, Fiedler F. Changes in the serum proteome of patients with sepsis and septic shock. Anesth Analg. 2006;103:1522-6.

11. Cambiaghi A, Pinto BB, Brunelli L, Falcetta F, Aletti F, Bendjelid K, et al. Characterization of a metabolomic profile associated with responsiveness to therapy in the acute phase of septic shock. Sci Rep. 2017;7:9748.

12. Cambiaghi A, Díaz R, Martinez JB, Odena A, Brunelli L, Caironi P, et al An innovative approach for the integration of proteomics and metabolomics data in severe septic shock patients stratified for mortality. Sci Rep. 2018:8:6681.

13. Beloborodova NV, Olenin AY, Pautova AK. Metabolomic findings in sepsis as a damage of host-microbial metabolism integration. J Crit Care. 2018;43: 246-55.

14. Bauzá-Martinez J, Aletti F, Pinto BB, Ribas V, Odena MA, Díaz R, et al. Proteolysis in septic shock patients: plasma peptidomic patterns are associated with mortality. Br J Anaesth. 2018;121:1065-74.

15. Aletti F, Conti C, Ferrario M, Ribas V, Bollen Pinto B, Herpain A, et al. ShockOmics: multiscale approach to the identification of molecular biomarkers in acute heart failure induced by shock. Scand J Trauma Resusc Emerg Med. 2016;24:9

16. Dobin A, Davis CA, Schlesinger F, Drenkow J, Zaleski C, Jha S, et al. STAR: ultrafast universal RNA-seq aligner. Bioinformatics. 2013;29:15-21. 
17. Liao Y, Smyth GK, Shi W. FeatureCounts: an efficient general purpose program for assigning sequence reads to genomic features. Bioinformatics. 2014;30:923-30.

18. Love Ml, Huber W, Anders S. Moderated estimation of fold change and dispersion for RNA-seq data with DESeq2. Genome Biol. 2014;15:550.

19. Subramanian A, Tamayo P, Mootha VK, Mukherjee S, Ebert BL, Gillette MA, et al. Gene set enrichment analysis: a knowledge-based approach for interpreting genome-wide expression profiles. Proc Natl Acad Sci. 2005;102: 15545-50.

20. Parenica J, Jarkovsky J, Malaska J, Mebazaa A, Gottwaldova J, Helanova K, et al. Infectious complications and immune/inflammatory response in cardiogenic shock patients: a prospective observational study. Shock. 2017; 47:165-74.

21. Dolinay T, Kim YS, Howrylak J, Hunninghake GM, An CH, Fredenburgh L, et al. Inflammasome-regulated cytokines are critical mediators of acute lung injury. Am J Respir Crit Care Med. 2012;185:1225-34.

22. Wiersinga WJ, Leopold SJ, Cranendonk DR, van der Poll T. Host innate immune responses to sepsis. Virulence. 2014;5:36-44.

23. Kawai T, Akira S. The role of pattern-recognition receptors in innate immunity: update on toll-like receptors. Nat Immunol. 2010;11:373-84.

24. Tsujimoto H, Ono S, Efron PA, Scumpia PO, Moldawer LL, Mochizuki H. Role of Toll-like receptors in the development of sepsis. Shock. 2008;29:315-21.

25. West XZ, Malinin NL, Merkulova AA, Tischenko M, Kerr BA, Borden EC, et al. Oxidative stress induces angiogenesis by activating TLR2 with novel endogenous ligands. Nature. 2010;467:972-6.

26. Kadl A, Sharma PR, Chen W, Agrawal R, Meher AK, Rudraiah S, et al. Oxidized phospholipid-induced inflammation is mediated by Toll-like receptor 2. Free Radic Biol Med. 2011:51:1903-9.

27. Richardson MB, Williams SJ. MCL and Mincle: C-type lectin receptors that sense damaged self and pathogen-associated molecular patterns. Front Immunol. 2014;5:1-9.

28. Kakihana Y, Ito T, Nakahara M, Yamaguchi K, Yasuda T. Sepsis-induced myocardial dysfunction; pathophysiology and management. J Intensive Care. 2016:4:22.

29. Rudiger A. Understanding cardiogenic shock. Eur J Heart Fail. 2015;17:466-7.

30. $\mathrm{Yu} \mathrm{L}$, Feng $\mathrm{Z}$. The role of Toll-like receptor signaling in the progression of heart failure. Mediators Inflamm. 2018;2018. https://doi.org/10.1155/2018/ 9874109.

31. Hochman JS. Cardiogenic shock complicating acute myocardial infarction: expanding the paradigm. Circulation. 2003;107:2998-3002.

32. Lawler PR, Mehra MR. Advancing from a "hemodynamic model" to a "mechanistic disease-modifying model" of cardiogenic shock. J Hear Lung Transplant. 2018;37:1285-8.

33. Xiang M, Fan J. Pattern recognition receptor-dependent mechanisms of acute lung injury. Mol Med. 2010;16:69-82

34. Huber R, Pietsch D, Panterodt T, Brand K. Regulation of C/EBP $\beta$ and resulting functions in cells of the monocytic lineage. Cell Signal. 2012;24 1287-96.

35. Taccone FS, Stordeur P, De Backer D, Creteur J, Vincent JL. Y-Globulin levels in patients with community-acquired septic shock. Shock. 2009;32:379-85.

36. Tamayo E, Fernández A, Almansa R, Carrasco E, Goncalves L, Heredia M, et al. Beneficial role of endogenous immunoglobulin subclasses and isotypes in septic shock. J Crit Care. 2012;27:616-22.

37. Andaluz-Ojeda D, Iglesias V, Bobillo F, Almansa R, Rico L, Gandía F, et al. Early natural killer cell counts in blood predict mortality in severe sepsis. Crit Care. 2011;15:R243

38. Venet F, Gebeile R, Bancel J, Guignant C, Poitevin-Later F, Malcus C, et al. Assessment of plasmatic immunoglobulin $\mathrm{G}$, a and $\mathrm{M}$ levels in septic shock patients. Int Immunopharmacol. 2011;11:2086-90.

39. Andaluz-Ojeda D, Iglesias V, Bobillo F, Nocito M, Loma AM, Nieto C, et al. Early levels in blood of immunoglobulin $\mathrm{M}$ and natural killer cells predict outcome in nonseptic critically ill patients. J Crit Care. 2013;28:1110 e71110.e10.

40. Binder CJ. Natural IgM antibodies against oxidation-specific epitopes. J Clin Immunol. 2010;30:S56-60.

41. Bermejo-Martin JF, Giamarellos-Bourboulis EJ. Endogenous immunoglobulins and sepsis: new perspectives for guiding replacement therapies. Int J Antimicrob Agents. 2015;46:S25-8.

42. Ren B, Cam H, Takahashi Y, Volkert T, Terragni J, Young RA, et al. E2F integrates cell cycle progression with DNA repair, replication, and G2/M checkpoints. Genes Dev. 2002;16:245-56.
43. Helin K. Regulation of cell proliferation by the E2F transcription factors. Curr Opin Genet Dev. 1998:8:28-35.

44. Hotchkiss RS, Monneret G, Payen D. Sepsis-induced immunosuppression: from cellular dysfunctions to immunotherapy. Nat Rev Immunol. 2013; 13:862-74.

45. Lewis AJ, Billiar TR, Rosengart MR. Biology and metabolism of sepsis: innate immunity, bioenergetics, and autophagy. Surg Infect. 2016;17:286-93.

46. Dewitte A, Lepreux S, Villeneuve J, Rigothier C, Combe C, Ouattara A, et al. Correction to: Blood platelets and sepsis pathophysiology: a new therapeutic prospect in critically ill patients? Ann Intensive Care. 2018:8:32.

47. Davenport EE, Burnham KL, Radhakrishnan J, Humburg P, Hutton P, Mills TC, et al. Genomic landscape of the individual host response and outcomes in sepsis: a prospective cohort study. Lancet Respir Med. 2016:4:259-71.

48. Marshall JC. Why have clinical trials in sepsis failed? Trends Mol Med. 2014; 20:195-203.

49. Harjola VP, Mebazaa A, Čelutkiene J, Bettex D, Bueno H, Chioncel O, et al. Contemporary management of acute right ventricular failure: a statement from the Heart Failure Association and the Working Group on Pulmonary Circulation and Right Ventricular Function of the European Society of Cardiology. Eur J Heart Fail. 2016;18:226-41.

50. Lawler PR, Fan E. Heterogeneity and phenotypic stratification in acute respiratory distress syndrome. Lancet Respir Med. 2018:6:651-3.

51. Hyman DM, Puzanov I, Subbiah V, Faris JE, Chau I, Blay JY, et al. Vemurafenib in multiple nonmelanoma cancers with BRAF V600 mutations. N Engl J Med. 2015;373:726-36.

\section{Publisher's Note}

Springer Nature remains neutral with regard to jurisdictional claims in published maps and institutional affiliations.
Ready to submit your research? Choose BMC and benefit from:

- fast, convenient online submission

- thorough peer review by experienced researchers in your field

- rapid publication on acceptance

- support for research data, including large and complex data types

- gold Open Access which fosters wider collaboration and increased citations

- maximum visibility for your research: over $100 \mathrm{M}$ website views per year

At $\mathrm{BMC}$, research is always in progress.

Learn more biomedcentral.com/submissions 